\title{
Agribot: lot Based Farmbot for Smart Farming
}

\author{
Jignyasa Sanghavi ${ }^{*}$, Rina Damdoo ${ }^{2}$, and Kanak Kalyani ${ }^{3}$ \\ ${ }_{1,2,3}$ Assistant Professor, Shri Ramdeobaba College of \\ Engineering and Managment, Nagpur, M.S. India
}

\begin{abstract}
Agriculture has been always the important occupation of the country like India where two-third of the population is dependent on it for their livelihood. The traditional system of agriculture is mostly dependent on the natural resources which sometimes yield good production and sometimes in losses. Moreover, proliferative population, decrease in farming land, natural calamities like drought, unwanted heavy rainfall and storms worsen the situation. However from the past few decades, various scientific innovations have changed the agricultural and farming techniques with time. IoT, AI and Machine learning techniques are used for smart farming to get the good crop yield. In this paper, an IOT based technology platform is proposed for farming. The farming bot "Agribot" proposed in this paper is equipped with the significant sensor for keeping track of environmental parameters on which farming is dependent. The android application with this bot provides view of data extracted from all the sensors and pictures of the crop/veggies grown in farm at regular basis so that one can monitor it at their finger-tip from any place. It also performs data analytics on the sensor data for calculating watering time intervals for the specific crop which can be viewed in android Application.
\end{abstract}

KEY WORDS: SMART FARMING, IOT, FARMING BOT, SENSORS, DATA ANALYSIS, WATERING PLANT INTERVAL PREDICTION.

\section{INTRODUCTION}

The current world population of the world is 7.8 billion according to the most recent United Nations estimates elaborated by Worldometer. The United Nations projects world population to reach 10 billion in the year 2057. This global population blast will become world scale problem resulting in food shortage, urbanization which will decrease the farming land and increase in demand for all the resources. Food is the basic requirement and production with good crop yield becomes the basic necessity for any country for their national stability.

\section{ARTICLE INFORMATION}

Received 7th Oct 2020 Accepted after revision 26th Dec 2020 Print ISSN: 0974-6455 Online ISSN: 2321-4007 CODEN: BBRCBA

Thomson Reuters ISI Web of Science Clarivate Analytics USA and Crossref Indexed Journal

\section{Clarivate
Analytics}

NAAS Journal Score 2020 (4.31) SJIF: 2020 (7.728)

A Society of Science and Nature Publication,

Bhopal India 2020. All rights reserved.

Online Contents Available at: http//www.bbrc.in/

Doi: http://dx.doi.org/10.21786/bbrc/13.14/21
The main factors affecting this occupation are rainfall, soil quality, temperature, and other climatic conditions. The soil testing is done manually for checking the fertility of land. The water quantity required for various crops/ veggies is different. Sometimes water is wasted in the fields; however drop irrigation techniques are used in some places. The sudden changes in climatic conditions can adversely affect the production. All such problems can be solved up to certain extend using innovative automated solutions. With the boom of smart cities all over the world, agriculture is also equipped with smart farming. IoT based sensors can be used for monitoring atmospheric pressure, atmospheric moisture, amount of sunlight, rainfall, pest infestation, soil moisture and nutrition.

The data extracted from these sensors can be used for data analysis and decision making. If sensors are attached with Bots, the data extracted can be used for taking appropriate actions like watering the crops/plants with specific amount of water on proper time, spraying fertilizers in proper amount, taking pictures of the plant for monitoring and disease detection, etc. Furthermore,

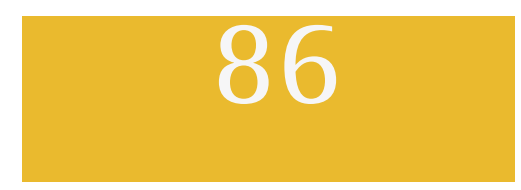


this smart Bots can be connected with smartphones, which will help to access the data from anywhere in the world. The smartphones can be used as dashboards giving all the brief of particular land. This combination of devices will prove to be beneficial in smart farming. IoT proves to be beneficial to agricultural supply chain and provide a critical technology for establishing a smooth flow of agricultural logistics. The Key advantages of Smart farming are:

1. Proper water management preventing the wastage of water.

2. Soil Management for checking $\mathrm{pH}$ level and moisture in the soil.

3. Crop Monitoring using cameras to detect infections and diseases in crop.

4. Weather monitoring for live monitoring and crop sowing time.

Related work: With advancement in technologies IoT frameworks and platforms has been used in many domains like smart healthcare, smart cities, etc. but still in agriculture domain large scale use of IoT solutions is not seen in many countries. In this section we tried to describe some of the IoT based solutions proposed by some of the researchers. Anand Nayyar et.al proposed a Smart IoT based gadget "Agriculture Stick" which assists farmers in getting Live Data (Temperature, Soil Moisture) for efficient environment monitoring. This stick was developed with the combination of Arduino, Cloud computing and Solar Technology using Breadboard mixed with various sensors. Thingsspeak.com was used to get the live data feed. The author claimed the accuracy of $98 \%$ in the data feeds extracted from the sensors . Andreas Kamilaris et.al developed Agri-IoT, a semantic framework for IoT based smart farming applications, which supports reasoning over various heterogeneous sensor data streams in real-time.

Framework also supports large-scale data analytics and event detection, ensuring seamless interoperability among sensors, services, processes, operations, farmers and other relevant actors, including online information sources and linked open datasets and streams available on the Web. For the experimentation of this project they deployed 100-300 sensors in the field. The comparative analysis of two RDF Stream Processing (RSP) engines CSPARQL and CQELS is illustrated with the results. Amandeep et.al proposed the GPS based remote controlled vehicle which can operate on both automatic and manual modes, for various agriculture operations like spraying, cutting, weeding etc. It can also monitor the temperature, humidity, soil condition and water supply. The researchers came with the concept of connected farm, which can provide suitable environment for growing crops. In this project all sensors and actuators used for monitoring and growing crops were connected with a gateway installed with a device software platform for IoT systems, called \&Cube.

The IoT service server "Mobius" was used to monitor the environmental condition of the connected farm, to communicate with expert farming knowledge systems and controls actuators according to it. The experiment suggested that different crops can be cultivated on a single field by dividing the land in the grid format and installing the automatic plant irrigation system which consists of soil sensors, water level indicators and chemical sprinkler. Information about the field can be extracted from GSM+ARDUINO system. For data analysis they used Things for visualization. They also used Speak, an open source platform for future records or if the GSM fails due to some technical errors. Some of the researchers tried to use IoT based solutions with Precision Agriculture. Precision Agriculture mainly includes data collection, processing and variable rate applications of inputs. Precision agriculture is one of the paradigms which can use the IoT advantages to optimize the production efficiency across the agriculture fields, optimize the quality of the crops, and minimize the negative environmental impact.

They proposed internet of things can be used to collect local information data like water level, temperature, humidity, soil moisture, and light from the various crop on precision agriculture. Li Hong-ying et.al proposed the maximum yield of the crop can be reached in the given environment using the time series techniques with past yield data for employing on a forecasting model. The crop yield forecasted model was tested in Liaoning Province in China from 1949 to 2005. Some researchers tried to implement Decision Tree Classifier on the environmental parameters for the prediction of crop to get the good yield. The following sections will introduce the proposed system in detail.

The Proposed System: This paper briefs the working and methodology of the proposed system. The hardware system used in this project is based Computerized Numerical Control (CNC) machine which provides free arm for movement in a confined area. This arm is fitted with a soil moisture sensor, humidity sensor, light detecting sensor, temperature sensor, small camera and water outlet pipe for watering the plants. These sensors help in monitoring the environment and its effect on the crops. This device is connected to internet so that it can provide real-time data of all above sensors on the smartphone. This data can be used for analytics purpose and for applying any machine learning algorithm for good crop yield. This project is majorly divided into the following parts:

1. Agribot Structure

2. Hardware Devices

3. Software Component

4. Android Application Development

5. Data-Analytics

\section{Agribot Structure}

X-Axis: The structure is made from a wooden block. In figure 1, the diagramatic representation of the hardware structure is shown. In this block, 2 smooth rods are running parallel to each other and fitted with the linear bearing for the smooth motion of the gantry (the structure that supports y and z-axis). The forward 
and backward motion is achieved by converting rotation motion into linear motion. For this, the threaded rod is placed in between the block. The motion to this rod is provided by a stepper motor.

Y-Axis: The $\mathrm{y}$-axis structure is similar to the $\mathrm{x}$-axis as shown in figure 1 . The only difference is that the structure stands on the X-axis (as Gantry) and not lay down. The motion is again provided by rotation of the threaded rod. This axis performs the left and right motion.

Z-Axis: The Z-axis performs upward and downward motion and based on the same principles as $\mathrm{x}$ and $\mathrm{y}$ axis works. The z-axis is connected with a head, which has the connection for soil moisture sensor and water outlet pipe. Combining all 3 axis $\mathrm{X}, \mathrm{Y}$ and $\mathrm{Z}$ we get a 3-D axis motion, where the head can be moved to any point in the confined space and the plants are planted in a grid format (for ex. 4 x 4 grid planting). In this architecture the benefit of multi-cropping by planting different plants in the different grid can also be taken. Every grid is associated with its column and row number as in a matrix.

Figure 1: Diagrammatic structure of Agribot Model

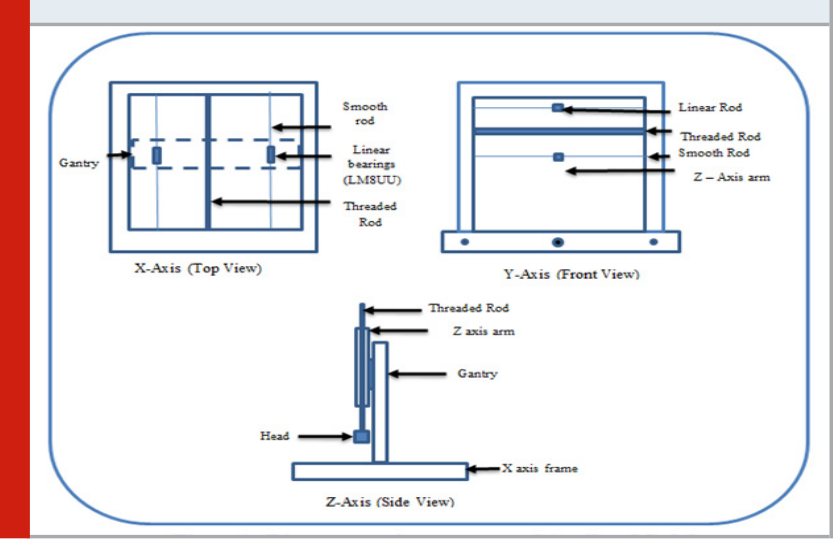

Hardware Devices

1. Raspberry pi-3: It acts as a CPU for the system and manages all the internet related Activity. It gives command to Arduino for performing tasks like moving the head to a particular location, watering the soil, check sensor readings, taking pictures of the plant and uploading pictures in the database.

2. Arduino Uno: All the sensors are connected to Arduino. It controls the revolution of stepper motor using A4988 stepper motor driver. It is directly connected to the raspberry pi through the USB interface and it follows the commands given by Raspberry pi.

3. Stepper Motor and Stepper Motor Driver (A4988): This Stepper motor can be controlled precisely with different steps. The set of 3 stepper motors is used in $\mathrm{X}, \mathrm{Y}$ and $\mathrm{Z}$ axis attached with the threaded rod to provide a $3 \mathrm{D}$ motion to the head. This motor is controlled by Arduino using motor driver A4988, this motor is powered by a $12 \mathrm{v}$ DC.

4. Temperature and humidity sensor, LDR, Soil Moisture sensor, Camera, Water pump, Relay: These sensors are attached to Arduino and share the real-time data with it. The relay is used to ON power pump from an external power source. The relay is turned $\mathrm{ON}$ and plants are watered as per requirement only, when the soil moisture sensor detects low moisture in soil.

Software Components: The preliminary software of this project manages the movement of the arm in the confined region. The soil moisture sensor attached with the arm is pressed under soil for checking an accurate moisture level. Taking into account values of all sensors, threshold value is fixed and depending on it decision is taken whether to water the plant or not. The pictures are captured of the plant from above with a camera attached to the arm top. These pictures are sent to the Firebase database. Collaterally it also uploads the sensor's values, so a user can get additional information about the day. This collected data can be further used for Data-Analytics process.

Android Application Development: An android application is developed for tracking details of all the sensors. This android app can act as live surveillance of the plant. The information extracted from sensors, stored in the raspberry-pi is send to the firebase database. The database can be accessed by the mobile application. The graphical representation of the sensor data for each day, navigation bar with different functionalities such as pictures of the plants, etc. can be viewed from this application. This data can be further used for data analysis using machine learning algorithms or forecasting algorithms.

Data-Analytics: One of the significant parts of the project is applying a Data-Analytics on the collected data of temperature, the moisture of environment, amount of sunlight and soil moisture for different plants. The weather data of that region is collected from different websites. This data can help in analysing the specific and precise need of the water for the different plants. This can result in efficiency in the watering of the plants and thus can increase the overall performance of the device.

The input for the analytics is the data extracted from sensors for temperature, environmental moisture, sunlight intensity and soil moisture. The system analyses the data and gives output of the duration or the interval of the time the device will wait to water the plant next time. Here, the water requirements for the plants are predicted through data-analytics and Machine Learning algorithms. For example after analysing 2 days data of a medium grown Tulsi plant, it depicts the variation of soil moisture according to the surrounding temperature, sunlight, and humidity. The data visualization shows the amount of sunlight increases as the day starts, reaching a peak point and falling again at the time of sunset.

The temperature follows the same pattern as of sunlight; Humidity has little variation but has a drastic effect on soil moisture. The pattern of soil moisture is inverse, low level of moisture when other data are increasing and retain less water in the soil and also seen vice versa. This 
pattern is due to the two reasons: (1) High evaporation rate: Evaporation rate during hot day is much higher than the rate during the cool night. (2) Transpiration pull: It is the pull created by the plant on the underground water to evaporate from leaves so the plant can get water and minerals through it. This data can be further used, when collected in abundant for different plants, for generating an accurate Machine Learning model for prediction of the time gap for watering various plants.

\section{CONCLUSION}

In this paper we tried to describe Agribot which is IoT based farmbot and will assist farmers for smart farming. It provides automated arm for watering the plants time to time and preventing from wastage of water. It also provides user all the details of environment and plant condition on finger tips using android application. It will reduce human intervention. The data is extracted from all the sensors and is used for the analysis. Machine learning algorithms or time series forecasting algorithms can be the future scope of this project which can determine the water needs of the plant, crop to be sown and other forecasting.

\section{REFERENCES}

Anand Nayyar and Vikram Puri. 2016. Smart Farming: IoT Based Smart Sensors Agriculture Stick for Live Temperature and Moisture Monitoring using Arduino, Cloud Computing \& Solar Technology. Proceedings of the International Conference on Communication and Computing Systems (ICCCS-2016), DOI: 10.1201/9781315364094-121.

Amandeep, Arshia Bhattacharjee, Paboni Das, Debjit Basu, Somudit Roy, Spandan Ghosh, Sayan Saha, Souvik Pain, Sourav Dey, T.K. Rana. 2017. Smart farming using IOT. 8th IEEE Annual Information Technology, Electronics and Mobile Communication Conference (IEMCON), Vancouver, BC, pp. 278-280, doi: 10.1109/IEMCON.2017.8117219.

Dewi C., Chen RC. 2020. Decision Making Based on IoT
Data Collection for Precision Agriculture. In: Huk M., Maleszka M., Szczerbicki E. (eds) Intelligent Information and Database Systems: Recent Developments. ACIIDS. Studies in Computational Intelligence, vol 830. Springer, Cham. https://doi.org/10.1007/978-3-030-14132-5_3.

Hariharr C Punjabi, Sanket Agarwal, Vivek Khithani, Venkatesh Muddaliar and Mrugendra Vasmatkar. 2017. Smart Farming Using IoT, International Journal of Electronics and Communication Engineering and Technology, 8(1), pp. 58-66.

Jun Wu, Anastasiya Olesnikova, Chi-Hwa Song, Won Don Lee. 2009. The Development and Application of Decision Tree for Agriculture Data. IEEE Second International Symposium on Intelligent Information Technology and Security Informatics. DOI 10.1109/ IITSI.2009.10

Kamilaris, F. Gao, F. X. Prenafeta-Boldu and M. I. Ali. 2016. Agri-IoT: A semantic framework for Internet of Things-enabled smart farming applications. IEEE 3rd World Forum on Internet of Things (WF-IoT), Reston, VA, 2016, pp. 442-447, doi: 10.1109/WFIoT.2016.7845467.

Li Hong-ying, Hou Yan-lin, Zhou Yong-juan, Zhao Huiming. 2012. Crop Yield Forecasted Model Based on Time Series Techniques. Journal of Northeast Agricultural University (English edition),Volume 19, Issue 1,Pages 73-77.

M. Ryu, J. Yun, T. Miao, I. Ahn, S. Choi and J. Kim. 2015. Design and implementation of a connected farm for smart farming system. IEEE SENSORS, Busan, pp. 1-4, doi: 10.1109/ICSENS.2015.7370624.

Xiaohui Wang and Nannan Liu. 2014. The application of internet of things in agricultural means of production supply chain management. Journal of Chemical and Pharmaceutical Research. Vol 6(7):pp. 2304-2310, ISSN: 0975-7384.

https://www.worldometers.info/world-population/. Last accessed on 15-09-2020. 